\title{
First report of naturally infected Sergentomyia minuta with Leishmania major in Tunisia
}

\author{
Kaouther Jaouadi ${ }^{1 * \dagger}$, Wissem Ghawar ${ }^{1{ }^{*} \dagger}$, Sadok Salem ${ }^{1}$, Mohamed Gharbi ${ }^{2}$, Jihene Bettaieb ${ }^{1}$, Rihab Yazidi ${ }^{1}$,
} Mariem Harrabi ${ }^{1}$, Omar Hamarsheh ${ }^{3}$ and Afif Ben Salah ${ }^{1}$

\begin{abstract}
Background: Many sand fly species are implicated in the transmission cycle of Leishmania parasites around the world. Incriminating new sand flies species, as vectors of Leishmania is crucial to understanding the parasite-vector transmission cycle in different areas in Tunisia and surrounding countries.

Findings: Seventy-four unfed females belonging to the genera Sergentomyia and Phlebotomus were collected in South Tunisia between June and November 2014, using sticky papers. PCR-RFLP (Restriction Fragment Length Polymorphism) analysis of the internal transcribed spacer 1 (ITS1) was used for Leishmania parasites detection and identification. Leishmania (L.) major (Yakimoff \& Shokkor, 1914) was identified within two Sergentomyia (S.) minuta (Rondani, 1843) and one Phlebotomus papatasi (Scopoli, 1786).

Conclusion: This is the first report of L. major identified from S. minuta in Tunisia. This novel finding enhances the understanding of the transmission cycle of $L$. major parasites of cutaneous leishmaniasis in an endemic area in South Tunisia.
\end{abstract}

Keywords: Leishmania major, Sergentomyia minuta, Phlebotomus papatasi, Cutaneous leishmaniasis, Tunisia

\section{Findings}

In Tunisia and other Old World countries, sand fly species of the genus Phlebotomus are traditionally regarded as the proven vectors of Leishmania parasites. However, a few studies have recently suggested the possible involvement of some species of the genus Sergentomyia in the transmission of Leishmania, particularly in some African countries [1-3]. There Sergentomyia spp. are the predominant sand fly taxa, and appear able to tolerate different biotopes and environmental conditions. Although, Sergentomyia spp. are proven vectors of reptile Leishmania spp. [4] which are non-pathogenic to humans, and at least some of them feed on humans and/or mammalian reservoirs which can contain Leishmania spp. pathogenic to humans [5]. Therefore, their role as vectors

\footnotetext{
* Correspondence: kaoutherj@gmail.com; ghawarwissemmed@yahoo.fr ${ }^{\dagger}$ Equal contributors

'Department of Medical Epidemiology, Laboratory of Transmission, Control and Immunobiology of Infections (LR11IPT02), Institut Pasteur de Tunis, 13 Place Pasteur BP-74, Tunis-Belvedere 1002, Tunisia

Full list of author information is available at the end of the article
}

in some visceral and cutaneous leishmaniasis foci where Sergentomyia spp. were abundant is suspected. Thus, the exact role of Sergentomyia spp. in transmitting mammalian leishmaniasis remains to be clarified [1, 2, 5-7].

An epidemiological study was carried out in Gafsa governorate in southwestern Tunisia, an old emerging focus of cutaneous leishmaniasis (CL), with the objective of detecting and characterizing novel vectors of Leishmania parasites in the region.

Sand fly collections were collected from June to November 2014, using sticky papers. Verbal informed consent was obtained from residents in each of the community. Specimens were sorted and transferred to $70 \%$ ethanol before being processed. Species identification was determined using the available morphological keys for sand fly in Tunisia [8]. Sand flies abdomens were transferred to individual sterilized $1.5 \mathrm{ml}$ vials and stored at $-20^{\circ} \mathrm{C}$. DNA from each individual female was extracted using the QIAamp ${ }^{\circ}$ DNA Mini Kit (QIAgen, Germany) according to the manufacturer's instructions. 
The presence of the Leishmania DNA was tested by the amplification of the ribosomal internal transcribed spacer 1 (ITS1) of these parasites and followed by Restriction Fragment Length Polymorphism (RFLP) analysis in which the ITS1-PCR products were digested by HaeIII restriction enzyme using protocol previously described [9]. The following WHO reference strains of Leishmania (L.) major, Leishmania killicki (Rioux, Lanotte \& Pratlong, 1986) and Leishmania infantum (Nicolle, 1908) were used as positives controls: L. major MON-25 MHOM/TN2009/ S600, L. killicki MON-8 MHOM/TN/2011/MX and $L$. infantum MON-1 MHOM/TN/94/LV50.

In total, 325 sand flies were captured and identified (190 males and 135 females). According to morphological identification, three species belonging to each genus Phlebotomus and Sergentomyia were identified: 162 Phlebotomus $(P$.) papatasi (Scopoli, 1786), 16 Phlebotomus (P.) (Larroussius) longicuspis (Nitzulescu, 1930), 5 Phlebotomus (P.) (Larroussius) perniciosus (Newstead, 1911), 67 Sergentomyia (S.) minuta (Rondani, 1843), 71 Sergentomyia (S.) fallax (Parrot, 1921) and 4 Sergentomyia (S.) dreyfussi (Parrot, 1933).

In this study, males were not considered regarding that only females were haematophageous. Indeed, fed females were excluded from the analysis because the presence of Leishmania DNA in these specimens can be an immediate consequence of blood feeding on an infected host. Only seventy-four unfed females belonging to $S$. minuta $(n=24), S$. fallax $(n=26), S$. dreyfussi $(n=4)$ and P. papatasi $(n=20)$ were tested for the presence of Leishmania parasites DNA which should be considered as the result of the multiplication of the parasites in the gut of the sand fly.
Two $S$. minuta and one $P$. papatasi were found positive for L. major DNA using the ITS1-PCR-RFLP method (Fig. 1). The detection of L. major in P. papatasi was not unexpected as this species has already been implicated as a vector of $L$. major in Tunisia [10]. However, our study is the first report of L. major infecting $S$. minuta in Tunisia, North Africa.

This preliminary finding raises the speculation and highlights the involvement of S. minuta in the zoonotic CL transmission cycle. Our results corroborate the finding in previous reports of $L$. major detection in $S$. minuta in Portugal [7] and in Sergentomyia ingrami (Newstead, 1914) in Ghana [3], respectively. L. major and Leishmania donovani (Laveran \& Mesnil, 1903) DNA have previously been reported in Indian Sergentomyia spp. [5]. Some authors have reported Sergentomyia spp. as a common human-biting species, including Sergentomyia (S.) schwetzi (Adler, Theodor \& Parrot, 1929) in Sudan [11], as well as Sergentomyia (Sintonius) clydei (Sinton, 1928) and Sergentomyia (Parrotomyia) africana (Newstead, 1912) [12]. Furthermore, Parvidens heischi (Kirk \& Lewis, 1950) (formerly considered as belonging to the Sergentomyia genus) is a very aggressive human biter [13]. Based on faunistic evidence, another study conducted in Senegal suggesting the implication of S. schwetzi and Sergentomyia dubia (Parrot, Mornet \& Cadenat, 1945) in the transmission of canine leishmaniasis [14]. In Mali, several specimens of Sergentomyia (Spelaeomyia) darlingi (Lewis \& Kirk, 1954) were found positive for L. major based on DNA screening [1]. Our results, in addition to those previously described, suggest that Sergentomyia species are involved in the transmission cycle of Leishmania parasites. Therefore, the prevailing opinion that leishmaniasis are strictly transmitted by sand

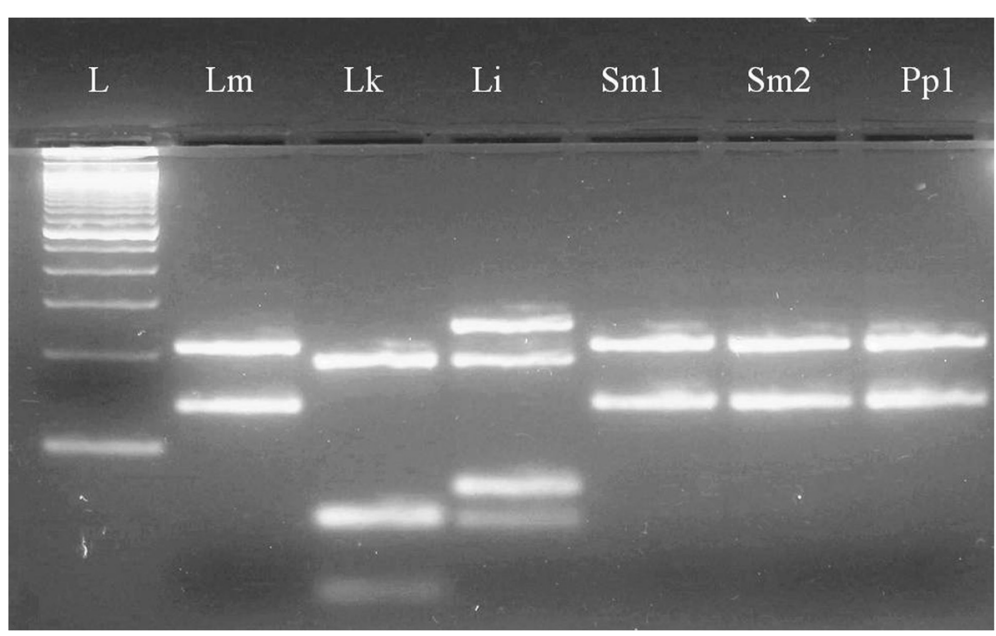

Fig. 1 RFLP products of the amplified ITS1 fragment using Haell enzyme. L: 100 bp size marker (Invitrogen ${ }^{\oplus}$ ), Lm: L. major MHOM/TN2009/S600 (two fragments of $132 \mathrm{bp}$ and 206-bp), Lk: L. killicki MON-8 /MHOM/TN/2011/MX (three fragments of 188-bp, 57-bp and 26-bp respectively), Li: L. infantum LV50 (three fragments of 187-bp, 72-bp and 55-bp respectively). Positive samples: Sm1 and Sm2 (two S. minuta individuals), and Pp1 (one P. papatasi) 
flies belonging to the Phlebotomus genus in the Old World is naïve.

The present study demonstrated, for the first time, the detection of $L$. major DNA in S. minuta from an endemic area of cutaneous leishmaniasis in South Tunisia. This illustrates the potential role of $S$. minuta in the transmission cycle of $L$. major in Tunisia, adding useful information to address the key epidemiological questions on this disease control. However, further research should be directed to investigate the actual role of Sergentomyia species in the transmission of Leishmania parasites in different endemic regions including blood meal analysis and parasite isolation, on larger samples of this genus, are now needed to confirm their respective roles as a potential vectors for zoonotic CL caused by L. major in Tunisia.

\section{Abbreviations}

CL: cutaneous leishmaniasis; ITS1: internal transcribed spacer 1; PCR: polymerase chain reaction; RFLP: Restriction Fragment Length Polymorphism; S.: Sergentomyia; spp.: species.

\section{Competing interests}

The authors declare that they have no competing interests.

\section{Authors' contributions}

$\mathrm{KJ}, \mathrm{WG}, \mathrm{MG}$ and $\mathrm{ABS}$ conceived, designed and coordinated the study. KJ, WG, SS and MH participated in field missions. KJ, WG, SS, JB, RY and MH performed the experiments. KJ, WG and OH drafted the manuscript. All authors approved the final version of the manuscript.

\section{Acknowledgements}

We are grateful to the staff of the Regional Directory of Public Health of Gafsa for their contribution to the achievement of this work. We would like to thank all the inhabitants that allowed the placement of the sticky traps in their properties. This study was supported by the Laboratory of Transmission, Control and Immunobiology of Infections (LR1 1IPT02), Institut Pasteur de Tunis.

\section{Author details}

'Department of Medical Epidemiology, Laboratory of Transmission, Control and Immunobiology of Infections (LR11IPT02), Institut Pasteur de Tunis, 13 Place Pasteur BP-74, Tunis-Belvedere 1002, Tunisia. ² Laboratory of Parasitology, National School of Veterinary Medicine, University of Manouba, 2020 Sidi Thabet, Tunisia. ${ }^{3}$ Department of Biological Sciences, Faculty of Science \& Technology, Al-Quds University, Jerusalem, Palestine.

Received: 13 October 2015 Accepted: 14 December 2015

Published online: 21 December 2015

\section{References}

1. Berdjane-Brouk Z, Kone AK, Djimde AA, Charrel RN, Ravel C, Delaunay P, et al. First detection of Leishmania major DNA in Sergentomyia (Spelaeomyia) darlingi from cutaneous leishmaniasis foci in Mali. PLoS One. 2012;7(1), e28266. doi:10.1371/journal.pone.0028266.

2. Kanjanopas K, Siripattanapipong S, Ninsaeng U, Hitakarun A, Jitkaew S, Kaewtaphaya P, et al. Sergentomyia (Neophlebotomus) gemmea, a potential vector of Leishmania siamensis in southern Thailand. BMC Infect Dis. 2013;13:333.

3. Nzelu CO, Kato H, Puplampu N, Desewu K, Odoom S, Wilson MD, et al. First detection of Leishmania tropica DNA and Trypanosoma species in Sergentomyia sand flies (Diptera: Psychodidae) from an outbreak area of cutaneous leishmaniasis in Ghana. PLoS Negl Trop Dis. 2014;8(2), e2630. doi:10.1371/journal.pntd.0002630.

4. Parvizi P, Amirkhani A. Mitochondrial DNA characterization of Sergentomyid sintoni populations and finding mammalian Leishmania infections in this sandfly by using ITS-rDNA gene. Iran J Vet Res. 2008;9(1):9-18.

5. Mukherjee S, Hassan MQ, Ghosh A, Ghosh KN, Bhattacharya A, Adhya S. Short report: Leishmania DNA in Phlebotomus and Sergentomyia species during a kala-azar epidemic. Am J Trop Med Hyg. 1997;57(4):423-5.
6. Mutinga MJ, Massamba NN, Basimike M, Kamau CC, Amimo FA, Onyido AE, et al. Cutaneous leishmaniasis in Kenya: Sergentomyia garnhami (Diptera Psychodidae), a possible vector of Leishmania major in Kitui District: a new focus of the disease. East Afr Med J. 1994;71(7):424-8.

7. Campino L, Cortes S, Dionisio L, Neto L, Afonso MO, Maia C. The first detection of Leishmania major in naturally infected Sergentomyia minuta in Portugal. Mem Inst Oswaldo Cruz. 2013;108(4):516-8. doi:S0074-02762013000400516.

8. Croset H, Rioux JA, Maistre M, Bayar N. The phlebotomines of Tunisia (Diptera-Phlebotominae). A revision of the systematics, distribution and behaviour [(author's transl)]. Ann Parasitol Hum Comp. 1978;53(6):711-49.

9. Schonian G, Nasereddin A, Dinse N, Schweynoch C, Schallig HD, Presber W, et al. PCR diagnosis and characterization of Leishmania in local and imported clinical samples. Diagn Microbiol Infect Dis. 2003:47(1):349-58.

10. Aoun K, Bouratbine A. Cutaneous leishmaniasis in North Africa: a review. Parasite. 2014:21:14. doi:10.1051/parasite/2014014.

11. Abonnenc E. Les phlébotomes de la région éthiopienne (Diptera, Psychodidae). Paris: Orstom (Memoires Orstom); 1972.

12. Hoogstraal H, Dietlein DR. Leishmaniasis in the Sudan Republic. 9. Ecological relationships of sandfly species and Leishmania infection. Am J Trop Med Hyg. 1963;12:165-74.

13. Quate LW. Phlebotomus sandflies of the Paloich area in the Sudan (Diptera, Psychodidae). J Med Entomol. 1964;1:231-68.

14. Senghor MW, Faye MN, Faye B, Diarra K, Elguero E, Gaye O, et al. Ecology of phlebotomine sand flies in the rural community of Mont Rolland (Thies region, Senegal): area of transmission of canine leishmaniasis. PLoS One. 2011;6(3), e14773.
Submit your next manuscript to BioMed Central and we will help you at every step:

- We accept pre-submission inquiries

- Our selector tool helps you to find the most relevant journal

- We provide round the clock customer support

- Convenient online submission

- Thorough peer review

- Inclusion in PubMed and all major indexing services

- Maximum visibility for your research

Submit your manuscript at www.biomedcentral.com/submit
CioMed Central 